\title{
HPLC-UV METHOD APPROACH FOR THE ANALYSIS AND IMPURITY PROFILING OF CAPTOPRIL
}

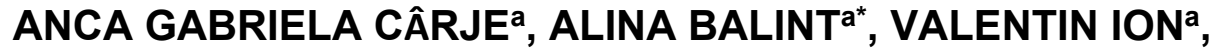 ANCA LUCIA POPb,c, DANIELA-LUCIA MUNTEANa, RALUCA SABĂUa, SILVIA IMREa}

\begin{abstract}
The aim of the study was to propose an improved HPLC/UV method for captopril impurity profiling based on forced degradation studies. Material and methods: the HPLC-UV analyses were performed on a Luna $\mathrm{C} 18$ column at $50{ }^{\circ} \mathrm{C}$ by using a mobile phase consisting of phosphoric acid $15 \mathrm{mM}$ and acetonitrile at $210 \mathrm{~nm}$. Results and discussions: an HPLC method with superior characteristics to one described in the European Pharmacopoeia for captopril impurities profiling was proposed. The main degradation product of captopril was captopril disulfide (Impurity A), the concentration of which increases in all the conditions of forced degradation, except thermal degradation. UV light has led to the highest number of unknown impurities, but the oxidative degradation presented the highest rate of degradation (>88\%). A total of 15 unknown impurities have been observed with significant area $(>0.50 \%)$, who were not initially present in the captopril sample. Conclusions: The proposed HPLC method can be successfully applied in pharmaceutical analysis laboratories as a stability indicating method of captopril, allowing the separation of official impurities $A, B, C, D$ and $E$ and those formed under forced degradation conditions.
\end{abstract}

Keywords: captopril, impurities, stability indicating method, degradation

a University of Medicine, Pharmacy, Sciences and Technology from Târgu Mureş, Faculty of Pharmacy, Gheorghe Marinescu street no 38, 540139, Târgu Mureş, Romania

b AC HELCOR, Dr. Victor Babeş street no 50, Baia Mare, 430092, Maramureş, Romania

c University of Medicine and Pharmacy „Carol Davila”, Faculty of Pharmacy, Traian Vuia Street no 6, 020956, Bucharest, Romania

*Corresponding author: alina.balint@umfst.ro 


\section{INTRODUCTION}

Captopril CPT (Figure 1), the first developed angiotensin-converting enzyme (ACE) inhibitor, is a specific inhibitor of angiotensin I discovered in 1977 and it is frequently used for the treatment of hypertension and some types of congestive heart failure. The antihypertensive effect of captopril is enhanced when it is given in combination with a diuretic or after salt depletion [1]. Biotransformation of captopril may involve both enzymatic and nonenzymatic processes. The biotransformation of CPT is predominantly produced at thiol group level: reversible disulfide bonds are formed with albumin and other proteins; other transformations in blood involve formation of disulfide dimer and mixed disulfides of CPT with L-cysteine and glutathione. Due to its pharmacological relevance, but also due to its frequent use in cardiovascular therapy, a significant number of methods for captopril determination from tablets or different biological samples, including chromatographic methods, are proposed [2-7].<smiles>CC(CS)C(=O)N1CCCC1C(=O)O</smiles>

Figure 1. Captopril ((2S)-1-[(2S)-2-Methyl-3-sulfanylpropanoyl]pyrrolidine-2carboxylic acid).<smiles>C[C@H](CSSC[C@H](C)C(=O)N1CCC[C@H]1C(=O)O)C(=O)N1CCC[C@H]1C(=O)O</smiles>

Figure 2. Captopril disulfide (1,1'-[Disulfanediylbis[(2S)-2-methyl-1-oxopropane3,1-diyl]]bis[(2S)-pyrrolidine-2-carboxylic] acid).

The pharmaceutical impurities may have a significant influence on the effects of a drug or may cause unwanted side-effects, therefore all the possible impurities of an active pharmaceutical ingredient (API) with concentrations above certain value must be detected, identified and quantified $[8,9]$. 
The present study aimed to propose a new HPLC-UV stability indicating method for CPT in the presence of its official impurities and related substances formed under forced degradation conditions: oxidative, acidic/ basic, thermal and natural/UV light exposure, respectively. Due to the presence of the thiol group in the molecular structure of captopril, a very reactive group, a particular attention was done to captopril disulfide formation during the studies (Figure 2) [10]. The analytical performances of the developed method as the linearity, accuracy and precision were determined. Contributions to kinetics of CPT degradation in solution have been made.

\section{RESULTS AND DISCUSSION}

\section{A. HPLC stability indication method development and optimization}

Firstly, the HPLC method described in the European Pharmacopoeia 9-th Edition for CPT was tested, following the official conditions: column - Luna C18 (Phenomenex) $300 \times 3.9 \mathrm{~mm}$ with $10 \mu \mathrm{m}$ particle size; mobile phase consisting of $75 \%$ phosphoric acid $15 \mathrm{mM}$ and $25 \%$ acetonitrile (ACN); flow rate $-1 \mathrm{ml} / \mathrm{min}$ [11]. The initial results being unsatisfactory (Figure 3 ), further tests were performed in order to optimize the method to serve the initial purpose and even to provide better performance characteristics: analysis time as short as possible, higher resolution, symmetrical and narrow peaks.

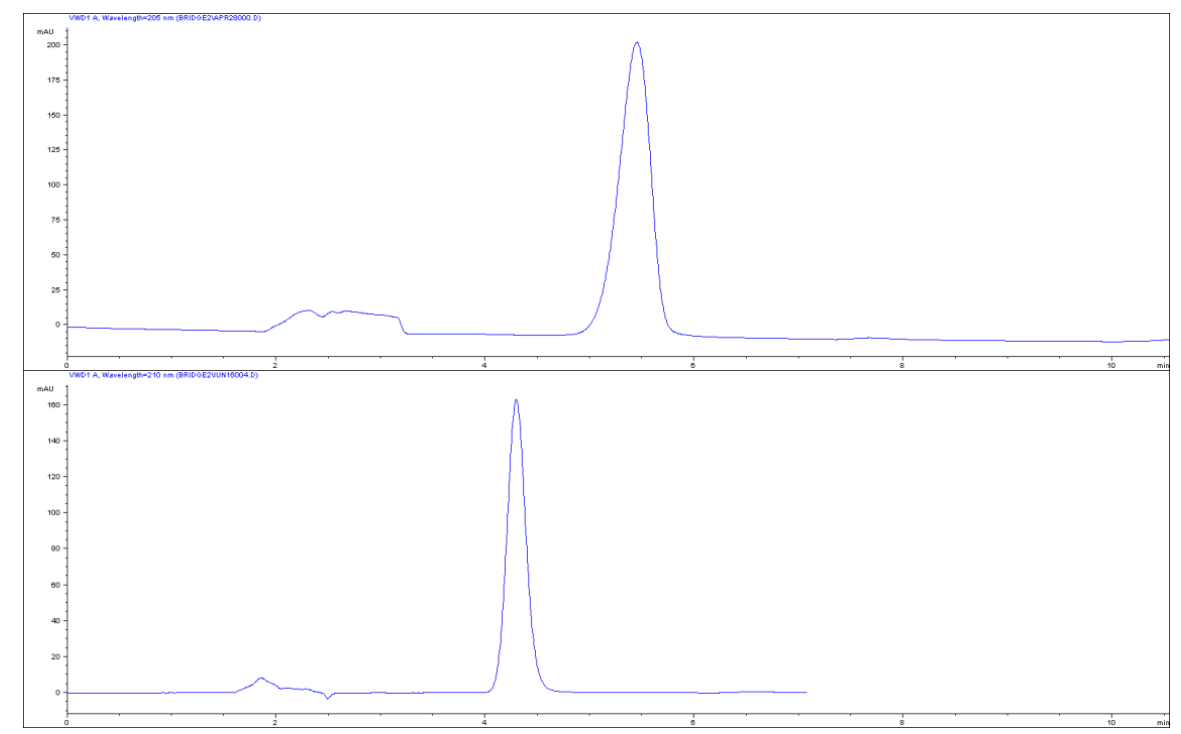

Figure 3. The chromatogram of CPT solution $(100 \mu \mathrm{g} / \mathrm{mL})$. Columns: a) Luna C18, $300 \times 3.9 \mathrm{~mm}, 10 \mu \mathrm{m}$ (Phenomenex); b) Luna C18 $250 \times 4.6 \mathrm{~mm}, 5 \mu \mathrm{m}$

(Phenomenex). Chromatographic conditions: mobile phase $75 \%$ phosphoric acid $15 \mathrm{mM}$ and $25 \% \mathrm{ACN}$; flow $1 \mathrm{~mL} / \mathrm{min} ; 210 \mathrm{~nm}$; column temperature $50^{\circ} \mathrm{C}$. 
Different chromatographic columns were tested and the column Luna C18 $250 \times 4.6 \mathrm{~mm}$ with $5 \mu \mathrm{m}$ particles, has been shown properties which allowed to attend the goals of the study. For the determination of known chemical-related impurities, identification was made by comparing the retention times determined by individual analysis of each known impurity with the retention times of the peaks in the analyzed samples (control samples and degraded samples). Thus, it was possible to discriminate and identify, as appropriate, the compounds present in the raw material from those formed following the controlled degradation of CPT.

By using a mobile phase consisting of phosphoric acid $15 \mathrm{mM}$ (solvent A) and $A C N$ (solvent $B$ ), different isocratic and gradient elution settings were verified due to the fact that the Impurity $C$ has a very similar chromatographic behaviour as Impurity E (Figure 4). Finally, a gradient elution was proposed which solved the interferences between CPT, its known impurities and those formed under forced degradation conditions. The method proposed by us provided the separation of the two impurities with similar chromatographic behaviour (Impurity $\mathrm{C}$ and $\mathrm{E}$ ) with a resolution equal to 1.57 .

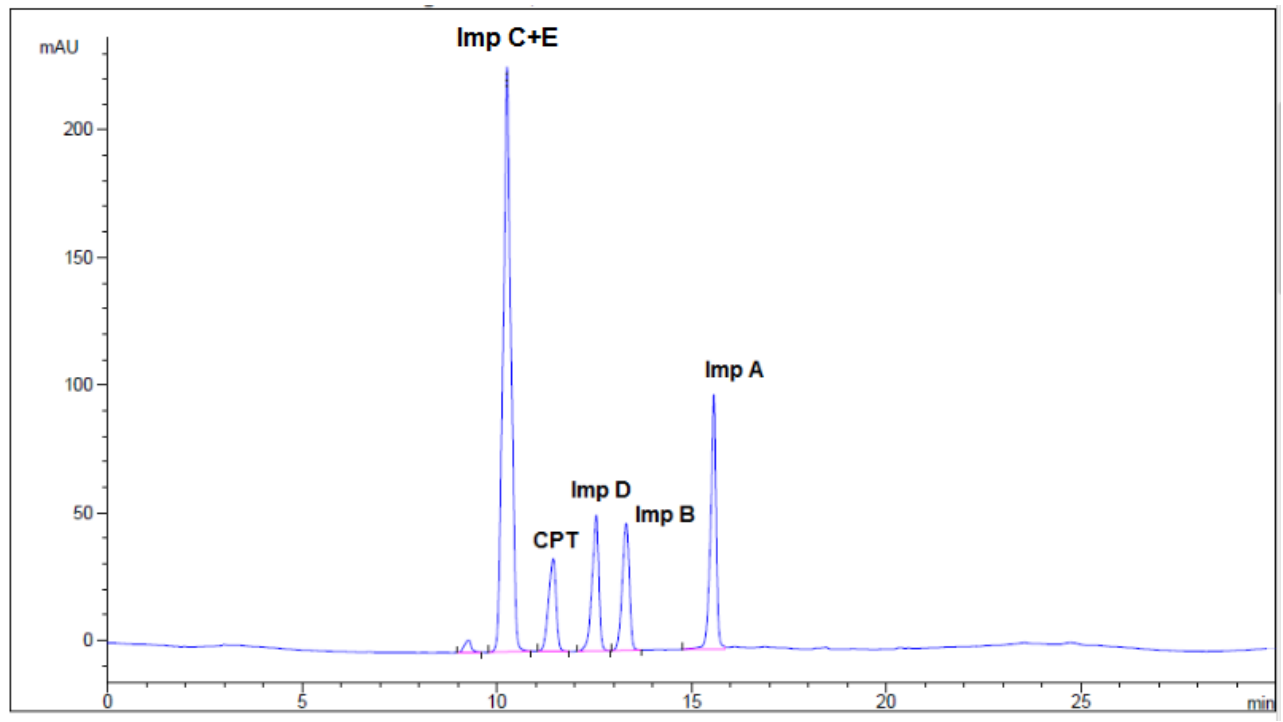

Figure 4. Chromatogram of a mixture of captopril (CPT) and impurities A, B, C, D, E. Chromatographic conditions: column Luna C18 250x4.6 mm, $5 \mu \mathrm{m}, 50^{\circ} \mathrm{C}$, gradient elution: $0-1 \mathrm{~min}: 90 \% \mathrm{~A}, 10 \% \mathrm{~B} ; 1-20 \mathrm{~min}: 90 \% \rightarrow 50 \% \mathrm{~A}$, respectively $10 \% \rightarrow 50 \% \mathrm{~B}$; flow rate $1.2 \mathrm{ml} / \mathrm{min}$; detection wavelength $210 \mathrm{~nm}$. 
Optimal HPLC experimental conditions were established at a column temperature of $50^{\circ} \mathrm{C}$ and the aqueous $\mathrm{pH}$ modifier component of the mobile phase was phosphoric acid $15 \mathrm{mM}$. The organic modifier, consisting of ACN, turned to be optimal and the gradient elution was done at a flow rate of 1.2 $\mathrm{ml} / \mathrm{min}$. The established chromatographic conditions allowed the separation of all studied impurities of captopril (A, B, C, D and E) in less than 20 minutes. The developed HPLC-UV method allowed the separation of all known impurities of the CPT with good reproducibility of retention times (RSD $<0.5 \%)$ and resolution $(R>1.5)$ (Figure 5).

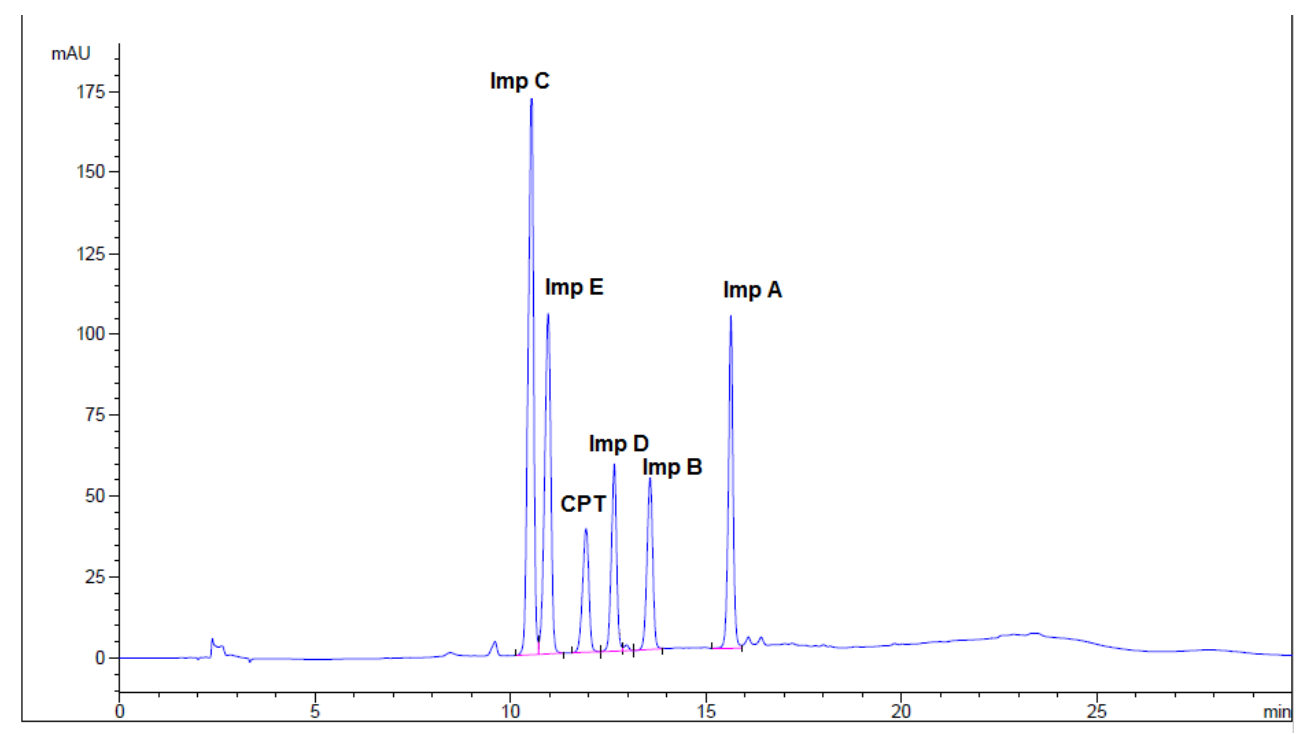

Figure 5. Chromatogram of a mixture of captopril (CPT) and impurities A, B, C, D, E. Chromatographic conditions: column Luna C18 250x4.6 mm, $5 \mu \mathrm{m} ; 50^{\circ} \mathrm{C}$; gradient elution $0-1 \mathrm{~min} 95 \% \mathrm{~A}-5 \% \mathrm{~B} ; 1-20 \mathrm{~min} 95 \% \rightarrow 50 \% \mathrm{~A} ; 50 \% \rightarrow 50 \% \mathrm{~B}$; flow rate $1.2 \mathrm{ml} / \mathrm{min}$; detection wavelength $210 \mathrm{~nm}$.

\section{B. The analytical performances of the method}

The main analytical validation parameters for the developed method were investigated as follows: specificity, linearity, accuracy and precision.

\section{Specificity}

Specificity was investigated regarding the interference of any other peak at the retention time of the principal peaks in blank solutions (solvent, extraction samples of the tablets excipients, degradation media). No peaks were detected from blank solutions at the retention time of the known peaks. CPT and its known impurities could be quantified from tablets without any interference from tablet excipients. 


\section{Linearity}

The linear regression equations (Table 1) were calculated for each impurity and CPT by using six concentration levels and three replicates per concentration level. The linearity range of the each impurity level and CPT has been chosen in order to include the limit of impurities allowed by the European Pharmacopoeia, 9th edition [11].

The linearity domain of CPT was established in the concentration range of $5-50 \mu \mathrm{g} / \mathrm{ml}$, similar to the main degradation product Impurity $A$, with the purpose of reporting the areas of possible unknown impurities to the area of CPT. The calibration curves were found to be linear with the correlation coefficient greater than 0.9998 over the ranges of concentrations shown in the table 1.

Table 1. The calibration curves characteristics for the CPT and its known impurities ( $N=6$ levels of concentration, $n=3$ replicates)

\begin{tabular}{|c|c|c|c|}
\hline Analyte & $\begin{array}{c}\text { Concentration } \\
\text { range, } \mu \mathrm{g} / \mathrm{ml}\end{array}$ & $\begin{array}{c}\text { The mean equation calibration } \\
\text { curve Area }=\text { slope }( \pm D S R \%) c+ \\
\text { intercept }\end{array}$ & $\mathbf{R}^{2}$ \\
\hline Impurity A & $5.02-50.2$ & Aria $=29.281 \times( \pm 0.675)+5.8008$ & 0.9999 \\
\hline Impurity B & $1.02-10.2$ & Aria $=56.692 \times( \pm 0.695)-0.6106$ & $>0.9999$ \\
\hline Impurity C & $0.9-9$ & Aria $=29.281 \times( \pm 1.549)+5.8008$ & 0.9998 \\
\hline Impurity D & $5.05-50.5$ & Aria $=5.377 \times( \pm 1.613)-1.33$ & 0.9989 \\
\hline Impurity E & $1-10$ & Aria $=83.039 x( \pm 0.695)-0.3624$ & $>0.9999$ \\
\hline CPT & $5.05-50.5$ & Aria $=40.002 \times( \pm 0.715)-4.1780$ & 0.9999 \\
\hline
\end{tabular}

The limit of detection (LOD) and quantification (LOQ) for CPT and its known ipurities was established in terms of peak height to background noise signal ratio. The values obtained for the investigated compounds are found in Table 2.

Table 2. The LOD and LOQ for the CPT and its known impurities

\begin{tabular}{lcc}
\hline Analyte & LOD $(\mu \mathrm{g} / \mathbf{m})$ & LOQ $(\mu \mathrm{g} / \mathbf{m})$ \\
\hline Impurity A & 0,882 & 2,648 \\
\hline Impurity B & 0,165 & 0,498 \\
\hline Impurity C & 0,345 & 0,837 \\
\hline Impurity D & 0,803 & 2,413 \\
\hline Impurity E & 0,156 & 0,469 \\
\hline \multicolumn{1}{c}{ CPT } & 1,130 & 3,394 \\
\hline
\end{tabular}




\section{The accuracy and the precision}

The accuracy and precision of the method were tested at two concentration levels (QCA and QCB) for each analyte and were expressed as recovery $\mathrm{Re} \%$ and relative standard deviation (RSD\%) of five replicates. As it can be noticed from the data contained in the table 3 the developed HPLC method has a recovery between $98 \%$ and $102 \%$ and a RSD below $2.0 \%$ for all studied analytes, values which are in agreement with pharmacopoeia regulations. For one of the two QC levels of concentration for Impurity D which is the lowest limit of quantification, the accuracy was $95.18 \%$ below the lower limit of accuracy. The method was considered proper in terms of accuracy for impurity $D$ taking into consideration the average of the two levels of concentration (98.4\%).

Table 3. The intra-series accuracy and the precision of the proposed HPLC method $(n=5)$

\begin{tabular}{|c|c|c|c|c|c|c|c|c|}
\hline \multirow[b]{2}{*}{ Analyte } & \multicolumn{5}{|c|}{ QCA } & \multicolumn{3}{|c|}{ QCB } \\
\hline & $\begin{array}{c}C_{T} \\
\mu / m \mathbf{l}\end{array}$ & $\begin{array}{c}C_{R}, \\
\mu \mathrm{g} / \mathrm{ml}\end{array}$ & $\operatorname{Re} \%$ & RSD\% & $\begin{array}{c}C_{T} \\
\mu \mathrm{g} / \mathrm{ml}\end{array}$ & $\begin{array}{c}C_{R}, \\
\mu \mathrm{g} / \mathrm{ml}\end{array}$ & $\operatorname{Re} \%$ & RSD\% \\
\hline CPT & 25.25 & 25.15 & 99.59 & 0.586 & 35.35 & 35.01 & 99.03 & 0.165 \\
\hline $\operatorname{Imp} A$ & 25.10 & 25.20 & 100.40 & 0.579 & 35.14 & 35.12 & 99.94 & 0.177 \\
\hline $\operatorname{Imp} B$ & 5.10 & 5.16 & 101.09 & 0.696 & 7.14 & 7.15 & 100.17 & 0.179 \\
\hline Imp C & 4.50 & 4.58 & 101.67 & 0.695 & 6.30 & 6.27 & 99.56 & 0.197 \\
\hline $\operatorname{Imp} D$ & 5.00 & 4.76 & $95.18^{*}$ & 1.257 & 7.00 & 7.11 & 101.62 & 1.360 \\
\hline $\operatorname{Imp} E$ & 5.00 & 5.05 & 100.91 & 0.561 & 7.00 & 7.01 & 100.19 & 0.154 \\
\hline
\end{tabular}

*below reference lower limit of accuracy

The method was applied for captopril assay from a commercially available product and the recovery was $100.99 \%$ with a RSD of $0.21 \%$. The product was in agreement to pharmacopoeia provisions in terms of CPT content.

\section{Degradation studies of captopril CPT in solution}

Once the optimal conditions have been established and analytical performance were verified, the stability studies of CPT solutions under different stress conditions have been applied. The stability studies of CPT were performed under various $\mathrm{pH}$ and temperature conditions, in the presence of strong oxidizing agents, but also under light (natural or UV) exposure to evaluate the potential degradation products and to distinguish it from other types of impurities that may be present in the final product [12]. 
The amount of remained captopril and the percentage of impurities obtained by degradation were determined by reporting the area obtained after the degradation of captopril under different stress conditions and the peak area obtained by the injection of CPT control (standard solution 0.5 $\mathrm{mg} / \mathrm{ml}$ ). Impurity A, captopril disulfide, was present in all samples subjected to degradation, including in the control sample but in a small concentration, probably formed by the degradation of CPT in the time elapsed between preparation and injection of the solution.

The main degradation product of CPT was captopril disulfide (Impurity A), as it was expected, the concentration of which increased in all the conditions of forced degradation, except thermal degradation $[13,14]$.

Analyzing our results, the amount of captopril degraded in the presence of UV light is $56.04 \%$, which means that more than half of the captopril was degraded within an hour by exposure to the UV lamp. This also explains the presence of 28 other peaks in the sample chromatogram, corresponding to other impurities, besides the main impurity, captopril disulfide. UV light has led to the highest number of unknown impurities for captopril as it can be observed in Figure 6 . These unknown impurities have a high hydrophilicity, eluting faster than CPT and the known related impurities. The degradation of CPT under the influence of UV light also leads to formation of related impurities $B(2.78 \mu \mathrm{g} / \mathrm{ml}), D(5.01 \mu \mathrm{g} / \mathrm{ml})$ and $E(0.97 \mu \mathrm{g} / \mathrm{ml})$.

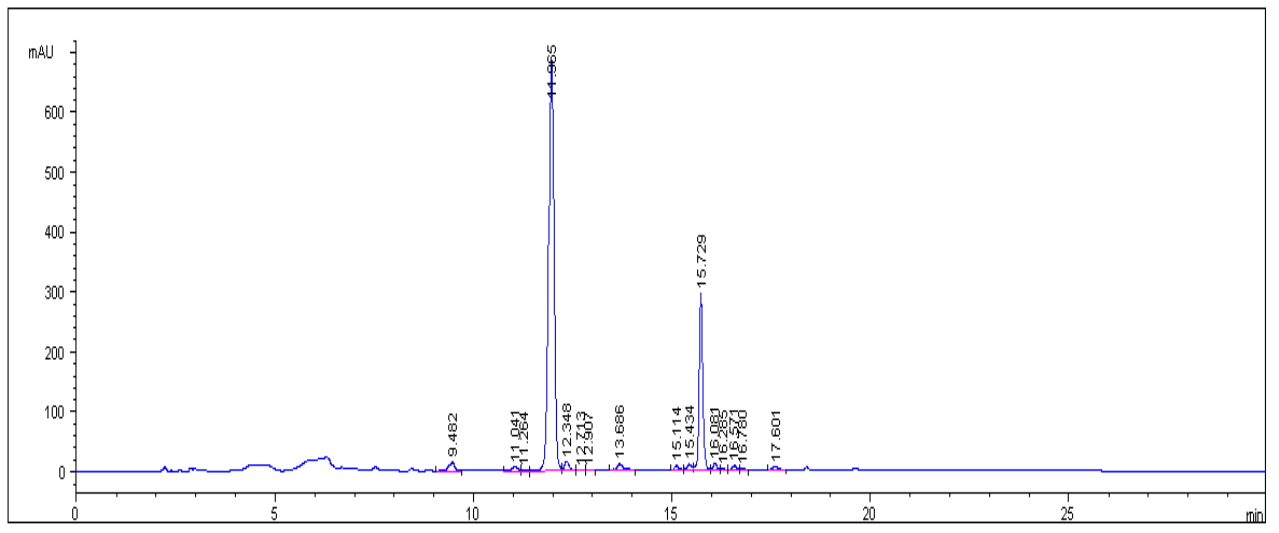

Figure 6. The chromatogram of CPT solution $(0.5 \mathrm{mg} / \mathrm{ml})$ after UV degradation.

The highest rate of CPT degradation is due to the presence of the oxidant agent, $\mathrm{H}_{2} \mathrm{O}_{2} 3 \%$, with a rate of degradation greater than $88 \%$, the main impurity formed in this case being the captopril disulfide (Impurity A) as it can be seen in the figures 7 and 8 . 


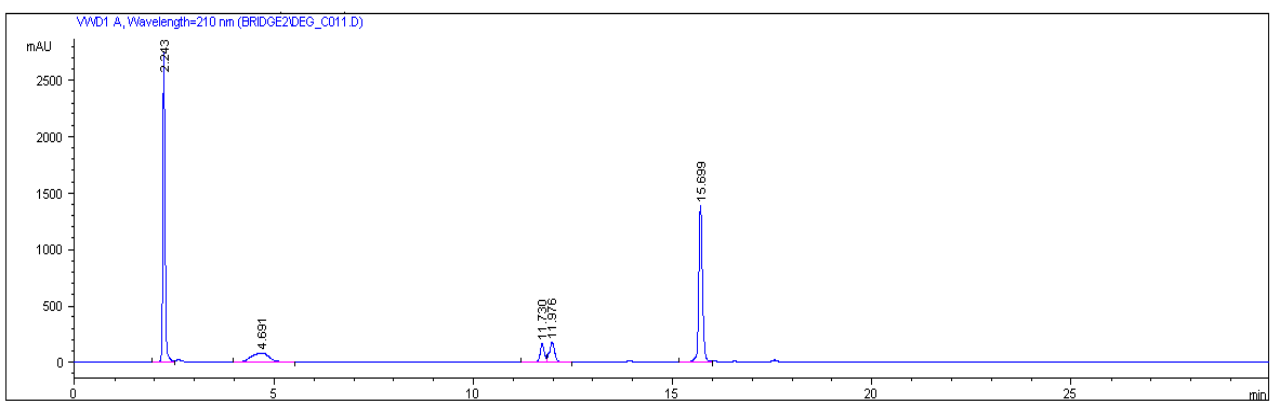

Figure 7. The chromatogram of CPT solution $(0.5 \mathrm{mg} / \mathrm{ml})$ after oxidative degradation.

Fifteen unknown impurities have been observed with a significant area $(>0.50 \%)$ and were not initially present in the analyzed CPT sample.

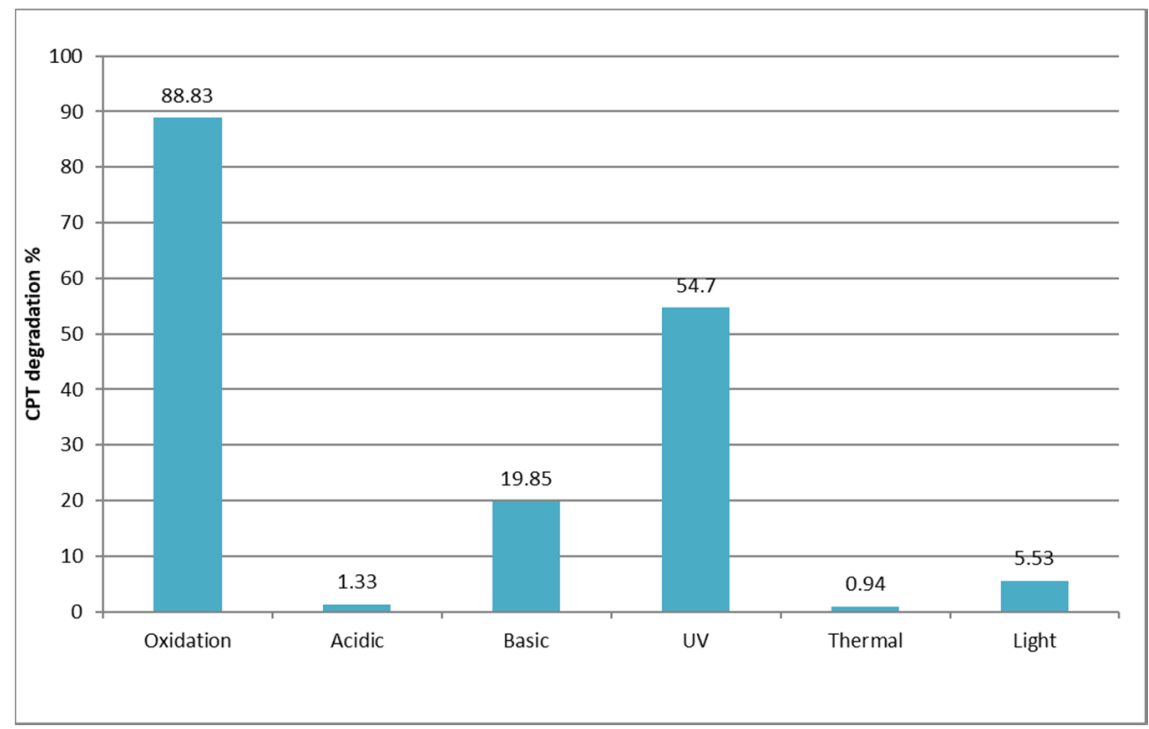

Figure 8. The degradation rate of CPT (\%) under different forced degradation conditions.

\section{The study of degradation kinetics under oxidative conditions}

The oxidant environment caused the most advanced degradation of all degradation conditions to which the captopril solution was subjected. The analysis of kinetic data has been established a mathematical model of simple zero kinetics in terms of CPT degradation to captopril disulfide (Impurity A) as it can be seen in the figure 9 . 
ANCA GABRIELA CÂRJE, ALINA BALINT, VALENTIN ION, ANCA LUCIA POP, DANIELA-LUCIA MUNTEAN, RALUCA SABĂU, SILVIA IMRE

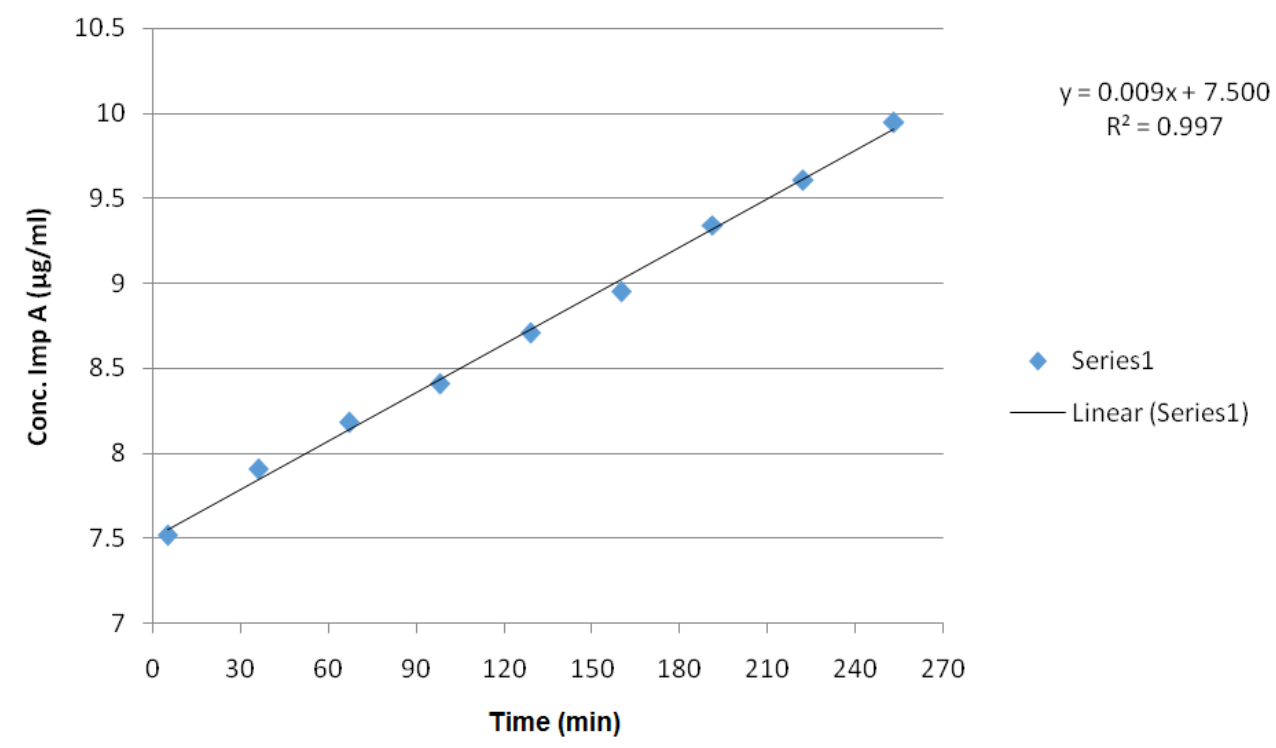

Figure 9. Simulation of zero order kinetics of oxidative degradation of CPT by monitoring the main degradation product captopril disulfide (Impurity A).

\section{CONCLUSIONS}

The developed method has superior characteristics in comparison to the official method of European Pharmacopoeia 9-th Edition for captopril related impurities profiling: an analysis time shorter with 15 minutes, very good resolution of the known impurities peaks $A, B, C, D$ and $E$ with excellent resolution and selectivity.

The main impurity formed in all cases of forced degradations, with the exception of thermal degradation, is captopril disulfide (Impurity A). In the presence of an oxidant environment, the CPT exhibits the highest rate of degradation, the main product being impurity $A$.

A total of 38 unknown impurities were revealed and 15 are present in a significant concentration.

The proposed HPLC method can be successfully applied in pharmaceutical analysis laboratories as a stability indicating method of CPT, allowing the separation of official impurities A, B, D, C and E and those formed under stressful conditions. 


\section{EXPERIMENTAL SECTION}

The analyses were performed on an Agilent 1100 Series LC system (Agilent Technologies, USA) equipped with a quaternary pump, an autosampler, a thermostated column compartment and a UV-VIS detector. The different types of chromatographic columns have been tested. The optimal separation conditions were obtained on a Luna C18 (2) 250 X $4.6 \mathrm{~mm}$ column containing $5 \mu \mathrm{m}$ size particle (Phenomenex, USA). Overall mobile phase for the LC separation was prepared by mixing different amounts of organic modifier with the variable amounts of aqueous buffer. The mobile phase consisting of phosphoric acid $15 \mathrm{mM}$ and acetonitrile (ACN) (LC Grade, Merck, Germany) was used. Detection was accomplished at $210 \mathrm{~nm}$ for captopril (CPT) and its impurities A, B, C, D and E (analytical purity, Sigma Aldrich). Mobile phases and other solutions were submitted to ultrasonication with a ultrasonic bath T700H (Elma Transsonic).

A Direct Q5 (Millipore, France) water purifier dispensing system was used for supplying the purified water and for $\mathrm{pH}$ buffer adjustments an InoLab $740 \mathrm{pH}$-meter (WTW, Germany) was used.

CPT (Sigma Aldrich) and its impurities A 1,1'-[disulfanediylbis[(2S)-2methyl-1-oxopropane-3,1- diyl]]bis[(2S)-pyrrolidine-2-carboxylic] acid (captopril disulfide, UPS), B (2S)-1-[(2S)-3-bromo-2-methylpropanoyl]pyrrolidine-2-carboxylic acid (EDQM), C (2RS)-2-methyl-3-sulfanylpropanoic acid (EDQM), D (2RS)-3bromo-2-methylpropanoic acid (EDQM) and E (2S)-1-(2-methylpropanoyl) pyrrolidine-2-carboxylic acid (EDQM) used as reference substances were analytical pure from Sigma Aldrich. All the standard solutions were prepared in methanol (LC Grade, Merck, Germany).

Sample solutions were prepared in methanol due to the low stability of captopril in aqueous solution by weighting an amount corresponding to a concentration of $1 \mathrm{mg} / \mathrm{ml}$ CPT for stock solution. The mixture of impurities was similarly processed, the concentrations of solutions for impurities $A, B$ and $E$ being $200 \mu \mathrm{g} / \mathrm{ml}, 2 \mathrm{mg} / \mathrm{ml}$ for impurity C, and $3 \mathrm{mg} / \mathrm{ml}$ for impurity D, respectively. Prior to analysis, the solutions of CPT, impurities and buffer solutions were homogenized and degassed for 10 minutes in the ultrasounds bath. The impurities mixture and captopril stock solution were prepared in methanol and maintained at $15^{\circ} \mathrm{C}$ during analysis to avoid any possible degradation.

The degradation studies were performed on solutions of CPT $5 \mathrm{mg} / \mathrm{ml}$ by subjecting to degradation the same volume of $0.5 \mathrm{ml}$. The acidic, basic and oxidative stress study consisted of adding $1 \mathrm{~mL}$ of the degradative agent $\left(\mathrm{HCl} 0.1 \mathrm{~N}, \mathrm{NaOH} 0.1 \mathrm{~N}\right.$ and $\mathrm{H}_{2} \mathrm{O}_{2} 3 \%$ ) to the captopril solution sample for 24 hours. The chemical degradation reaction was stopped by adding a suitable neutralizing agent after 24 hours. The thermal degradation consisted of 
ANCA GABRIELA CÂRJE, ALINA BALINT, VALENTIN ION, ANCA LUCIA POP, DANIELA-LUCIA MUNTEAN, RALUCA SABĂU, SILVIA IMRE

maintaining the CPT solution for one hour at a temperature of $60{ }^{\circ} \mathrm{C}$. The degradation of CPT under the influence of light was done by maintaining the CPT sample solution for 24 hours at natural light and for 1 hour under the influence of UV light at $254 \mathrm{~nm}$ (UV Lamp Vilber Lourmat, 6W with intensity at $\left.710 \mu \mathrm{w} / \mathrm{cm}^{2}\right)$. After degradation, all the solutions were made up to $5 \mathrm{ml}$ with a mixture of water and ACN 50:50 (v:v).

\section{ACKNOWLEDGMENTS}

This work was supported by a grant of the Romanian National Authority for Scientific Research and Innovation, CNCS/CCCDI - UEFISCDI, project number PNIII-P2-2.1-BG-2016-0115, within PNCDI III.

\section{REFERENCES}

1. I. Kancirová, M. Jašová, I. Waczulíková, T. Ravingerová, A. Ziegelhöffer, M. Ferko, Iranian Journal of Basic Medical Science, 2016,19(6), 615-623.

2. J. Leanpolchareanchai, J. Suksiriworapong, Journal of Pharmaceutical Sciences, 2015, 42(2), 85-92.

3. W.M. Mahmoud, K. Kümmerer, Chemosphere, 2012, 88, 1170-1177.

4. R. Nogueira, W. Wollinger, T.E. Da Silva et al, Brazilian Journal of Pharmaceutical Sciences, 2011, 47(2), 351-362.

5. S. Imre, S. Vancea, D.L. Muntean, E. Sipos, A. Cociş, V. Avrigeanu, E. Mircia, Revista Medico-Chirurgicală a Societăţii de Medici şi Naturalişti din laşi, 2008, 112(3), 848-855.

6. N. Rastkari, M. Khoob, A. Shafiee, M.R. Khoshayand, R. Ahmadkhaniha, Journal of Chromatography B, 2013, 932, 144-151.

7. J.R. Lino e Freitas, F.J Oliveira Quintao, J.C Cardoso da Silva et al, International Journal of Environmental Analytical Chemistry, 2017, 1, 42-55.

8. T. Rawat, I.P. Pandey, Journal of Pharmaceutical Sciences and Research, 2015, 7(5), 238-241.

9. M. Blessy, R.D. Patel, P.N. Prajapati, Y.K. Agrawal, Journal of Pharmaceutical Analysis, 2014, 4(3), 159-165.

10. M.R. Pabari, C. McDermott, J. Barlow, Z. Ramtoola, Clinical Therapeutics, 2012, 34, 2221-2229.

11. ${ }^{* * *}$ European Pharmacopoeia 9th edition, 2017.

12. ICH Expert Working Group - Stability testing of new drug substances and products, ICH Harmonised Tripartite Guideline, 2003.

13. A. Gindy, M.W. Nassar, K.A. Salam Attia, H.H. Abu-Seada, M. El-Ghandour, Journal of Liquid Chromatography \& Related Technologies, 2014, 37, 696-712.

14. S. Valizadeh, M. Rasekhi, H. Hamishehkar, M. Asadollahi, H. Hamishehka, Journal of Research Pharmacy Practice, 2015, 4(3),147-152. 